\title{
Pulmonary Artery Systolic Pressure
}

National Cancer Institute

\section{Source}

National Cancer Institute. Pulmonary Artery Systolic Pressure. NCI Thesaurus. Code C120943.

The blood pressure in the pulmonary artery during the contraction of the left ventricle of the heart. 